\title{
Nutrient uptake, allocation and biochemical changes in two Chinese fir cuttings under heterogeneous phosphorus supply
}

\author{
Taimoor Hassan Farooq ${ }^{(1)}$, \\ Mulualem Tigabu ${ }^{(2)}$, \\ Xiangqing $\mathrm{Ma}^{(1)}$, \\ Xianhua Zou ${ }^{(1)}$, \\ Aiqin Liu ${ }^{(1)}$, \\ Per Christer Odén ${ }^{(2)}$, \\ Pengfei Wu ${ }^{(1)}$
}

\begin{abstract}
Plant-available nutrients in soils are usually distributed in a heterogeneous or patchy manner. Plant responses to low levels of phosphorous (P) are not uniform across and within species. In this study, we examined the adaptive role of physiological plasticity (increased rate of nutrient uptake in localized zones) to the heterogeneous distribution of $P$ in the soil, and whether low $P$ stress transcends to the shoot and triggers similar biochemical changes that enhance tolerance. Two Chinese fir clones with high P efficiency $(M 1$, which is tolerant to low $\mathrm{P}$, and M4 which is able to decouple fixed $\mathrm{P}$ ) were chosen as the research materials and their physiological responses to low $P$ stress were examined using a sand culture experiment. For both clones, there was no significant difference in nutrient concentration between P-replete and P-deficient patches. Heterogeneous $P$ supply did not affect the allocation of nutrients to the above-ground parts of the plants. The activity of acid phosphatase (APase) and malondialdehyde (MDA) content increased initially but declined with increasing duration of stress, while the content of soluble protein and total chlorophyll contents remained unaffected by the heterogeneous $P$ supply. We conclude that physiological plasticity plays no role in adaptation to low $P$ stress in these clones, while the changes in APase activity and MDA content in needles suggest functional metabolic processes are involved in enhancing P-efficiency in these clones.
\end{abstract}

Keywords: Chinese Fir, Physiological Plasticity, Low Phosphorus Stress, Acid Phosphatase Activity, Nutrient Accumulation

$P$ rapidly form insoluble complexes with cations, particularly aluminum and iron (Xie \& Zhou 2002). P-deficiency in Chinese fir forest soils is opined as one of the most important causes of productivity decline over successive rotations (Wu et al. 2017, Chen 2003). $P$ is an essential elements for plant growth and development, and thus, $\mathrm{P}$ fertilization is essential for tree plantations (Alexova \& Millar 2013, Miguel et al. 2015).

The most sustainable method of $\mathrm{P}$ management is to screen out P-efficient genotypes that are effective at acquiring $P$ from the soil and its subsequent utilization (Shenoy \& Kalagudi 2005). In a previous study we screened two Chinese fir clones that are tolerant to low $\mathrm{P}$ and have the ability to decouple fixed $P$ (Wu et al. 2012). These
(1) College of Forestry, Fujian Agriculture and Forestry University, Fuzhou, 350002 Fujian Province (PR China); (2) Southern Swedish Forest Research Center, Faculty of Forest Science, Swedish University of Agricultural Sciences, PO Box 49, SE-230 53 Alnarp (Sweden)

@ Pengfei Wu (fjwupengfei@126.com)

Received: Oct 20, 2017 - Accepted: Mar 13, 2018

Citation: Farooq TH, Tigabu M, Ma X, Zou X, Liu A, Odén PC, Wu P (2018). Nutrient uptake, allocation and biochemical changes in two Chinese fir cuttings under heterogeneous phosphorus supply. iForest 11: 411-417. - doi: 10.3832/ifor2657-011 [online 2018-06-05]

Communicated by: Gianfranco Minotta clones displayed increased root proliferation, in the form of larger root surface area and root volume, in P-starved than P-replete patches (Wu et al. 2011b). However, it is not clear whether these root morphological responses influence the rate of nutrient uptake in localized zones (physiological plasticity), nutrient translocation to the shoot, and biochemical changes (acid phosphatase activity, malondialdehyde, soluble protein, and chlorophyll contents) in the needles.

There is a need for further research to understand, whether physiological plasticity plays a role in adaptation to the heterogeneous distribution of $P$ in soil, and whether the stress transcends to the shoot and triggers biochemical changes that enhance tolerance to low $\mathrm{P}$ stress. The main objective of this study was to examine the effects of heterogeneous $P$ supply on nutrient uptake, translocation, and biochemical changes in the needles of two Chinese fir clones with high tolerance to low $\mathrm{P}(\mathrm{M} 1)$ and the ability to decouple fixed $P\left(M_{4}\right)$. The hypotheses of the study were: (1) heterogeneous $\mathrm{P}$ distribution has no marked influence on the rate of nutrient uptake and its subsequent translocation (lack of physiological plasticity); (2) membrane lipid oxidation, measured by malondialdehyde (MDA) content, is the same for P-stressed and P-replete seedlings; (3) the activity of acid phosphatase (APase) in needles is 
higher in response to low P stress; and (4) low $\mathrm{P}$ stress reduces the content of soluble protein and total chlorophyll, when compared to normal P supply conditions.

\section{Materials and methods}

\section{Plant materials}

Two Chinese fir clones with high P-use efficiency (M1 and $M_{4}$ ) were chosen as test materials. M1 can tolerate low $P$ levels while $M_{4}$ has the ability to activate fixed phosphate (Fe-P) and make it available for plant use (Wu et al. 2011b). The cuttings of these clones were raised by reproductive cloning, and 1-year-old healthy cuttings of these clones were chosen for a sand culture experiment.

\section{Experimental design}

A sand culture experiment with heterogeneous $P$ supply was carried out in the greenhouse at the College of Forestry, Fujian Agriculture and Forestry University, China. Specially designed glass pots $(50 \mathrm{~cm}$ length, $25 \mathrm{~cm}$ width, $43 \mathrm{~cm}$ height) were made for $P$ stress simulation. Each pot was partitioned into two compartments (a Ppoor patch and a P-rich patch - Fig. 1), and then filled with $10 \mathrm{~kg}$ cleaned sand with no phosphorus. Seedlings were planted at the center of each pot with the root system carefully and equally divided into the two compartments of each plot. The following four treatments were applied after planting: no $\mathrm{P}$ supply in the $\mathrm{P}$-poor patch, and normal $P$ supply (1.0 mmol L $\mathrm{L}^{-1} \mathrm{KH}_{2} \mathrm{PO}_{4}$ ) in the P-rich patch (Po); $0.5 \mathrm{~g} \mathrm{Kg}^{-1}$ insoluble $\mathrm{FePO}_{4} \cdot \mathrm{H}_{2} \mathrm{O}$ in the P-poor patch and normal $\mathrm{P}$ supply in the P-rich patch (low level of fixed insoluble Fe-P, hereafter refereed to as $\mathrm{P} 1) ; 1.5 \mathrm{~g} \mathrm{Kg}^{-1}$ insoluble $\mathrm{FePO}_{4} \cdot \mathrm{H}_{2} \mathrm{O}$ in the
P-poor patch and normal $\mathrm{P}$ supply in P-rich patch (high level of fixed insoluble Fe-P, hereafter referred to as $\mathrm{P}_{2}$ ); and normal $\mathrm{P}$ supply in both compartments, hereafter referred to as $\mathrm{P}_{3}$ ). The Fe-P compound powder was mixed well with sterile dry sand in the P-poor patch before cuttings were planted in the pots. Three independently selected seedlings were used for each treatment resulting in a total of 24 pots.

In order to meet the other nutrients requirements for growth of the Chinese fir cuttings, macro-nutrients were added to each pot during the stress period with a modified Hoagland solution ( $\mathrm{Wu}$ et al. 2011a). This solution contained $5.0 \mathrm{mmol} \mathrm{L}^{-1}$ $\mathrm{KNO}_{3}, 2.0 \mathrm{mmol} \mathrm{L} \mathrm{MgSO}_{4} \cdot 7 \mathrm{H}_{2} \mathrm{O}, 5.0 \mathrm{mmol}$ $\mathrm{L}^{-1} \mathrm{Ca}\left(\mathrm{NO}_{3}\right)_{2} \cdot 4 \mathrm{H}_{2} \mathrm{O}, 1 \mathrm{ml} \mathrm{L}^{-1}$ FeEDTA, and Arnon micro-nutrients including $46.3 \mu \mathrm{mol} \mathrm{L}^{-1}$ $\mathrm{H}_{3} \mathrm{BO}_{3}, 0.3 \mu \mathrm{mol} \mathrm{L}{ }^{-1} \mathrm{CuSO}_{4} \cdot 5 \mathrm{H}_{2} \mathrm{O}, 0.8 \mu \mathrm{mol} \mathrm{L}^{-1}$ $\mathrm{ZnSO}_{4} \cdot 7 \mathrm{H}_{2} \mathrm{O}, 9.1 \mu \mathrm{mol} \mathrm{L}^{-1} \mathrm{MnCl}_{2} \cdot 4 \mathrm{H}_{2} \mathrm{O}$, and $0.4 \mu \mathrm{mol} \mathrm{L}^{-1} \mathrm{H}_{2} \mathrm{MO} \cdot 4 \mathrm{H}_{2} \mathrm{O}$. The $\mathrm{pH}$ of the nutrient solution was regulated to 5.5. The nutrient solution was added at a rate of $100 \mathrm{ml}$ per pot every 2 days. Each pot was supplied with $150 \mathrm{ml}$ distilled water every day at noon. The temperature in the greenhouse ranged from 18 to $28^{\circ} \mathrm{C}$ and relative humidity was $>80 \%$; the average photoperiod was $14 \mathrm{~h} \mathrm{~d}^{-1}$ (Zou et al. 2014).

\section{Biochemical analyses}

During the 2 months of stress period, needles were sampled every 20 days to measure the following physiological variables: malondialdehyde (MDA) content, acid phosphatase (APase) activity, soluble protein content, and chlorophyll content. The MDA content was determined by coloration method using thiobarbituric acid (Ao et al. 2007). For each treatment, a sample of $0.25 \mathrm{~g}$ needles per replicate was

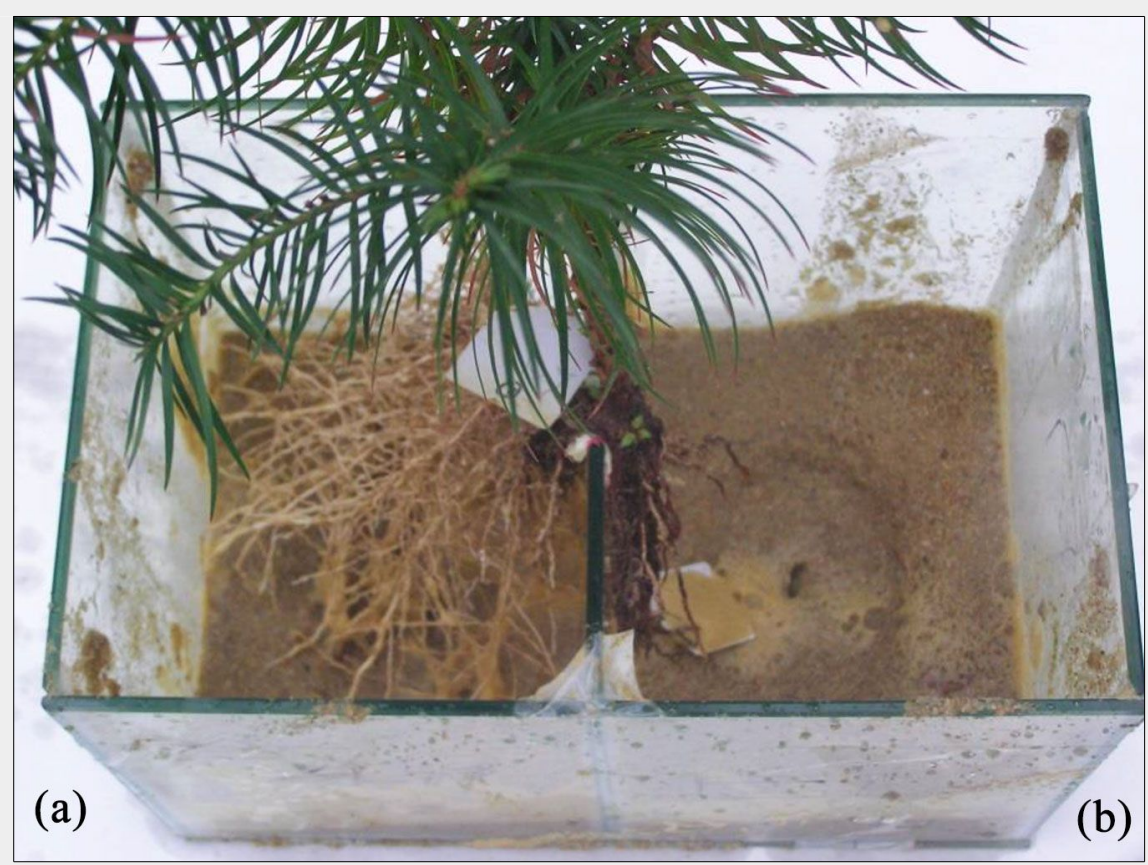

Fig. 1 - The design pot used for the heterogeneous phosphorus stress experiment. (a) P-poor patch; (b) P-rich patch. taken twice, weighed, and then ground in liquid nitrogen. To the ground samples $4 \mathrm{ml}$ $5 \%$ thiobarbituric acid (TBA) was added. The homogenate was transferred into centrifuge tubes and centrifuged for $10 \mathrm{~min}$ at $4,500 \mathrm{rpm}$. We extracted $1.5 \mathrm{ml}$-supernatant and added $2.5 \mathrm{ml}$ of $0.5 \% \mathrm{TBA}$, and the mixture was placed in a boiling water bath for $10 \mathrm{~min}$. Thereafter, the mixture was removed and the reaction was terminated in an ice bath (about $5 \mathrm{~min}$ ), and then centrifuged again for $10 \mathrm{~min}$ at $4,500 \mathrm{rpm}$. Finally, the supernatant was removed and the absorbance value was recorded at 532 $\mathrm{nm}$ and $600 \mathrm{~nm}$, with distilled water as a control (Tripathi et al. 2016).

APase activity was determined following the method of (McLachlan 1980), with slight modifications. From each treatment and replicate, $0.25 \mathrm{~g}$ needle samples were ground in liquid nitrogen and then $4 \mathrm{ml}$ pre-cooling extract of $0.1 \mathrm{~mol} \mathrm{~L}^{-1} \mathrm{NaAc}$ with a pH of 5.2 was added, extracted for $1 \mathrm{~h}$ in an ice bath, and then centrifuged for 25 $\min$ at $7,200 \mathrm{rpm}$. The APase reaction system consisted of $0.9 \mathrm{ml}$ of $0.1 \mathrm{~mol} \mathrm{~L}^{-1} \mathrm{NaAc}$ with a pH of 5.2, $0.9 \mathrm{ml}$ of $1 \mathrm{mmol} \mathrm{L}^{-1} \mathrm{p}-\mathrm{Ni}$ trophenyl phosphate (pNPP), and $0.9 \mathrm{ml}$ of $5 \mathrm{mmol} \mathrm{L}^{-1} \mathrm{CaCl}_{2}$. We then extracted $0.3 \mathrm{ml}$ of the APase enzyme solution. A total of 3 $\mathrm{ml}$ reaction mixture was heated in a $37{ }^{\circ} \mathrm{C}$ water bath for $30 \mathrm{~min}$. The reaction mixture was removed from the water bath and $1 \mathrm{ml}$ of $1 \mathrm{~mol} \mathrm{~L}^{-1} \mathrm{NaOH}$ was immediately added to terminate the enzymatic reaction. The mixture was then centrifuged for $25 \mathrm{~min}$ at $7,200 \mathrm{rpm}$ at $4{ }^{\circ} \mathrm{C}$, and the absorbance was recorded at $405 \mathrm{~nm}$. APase activity $\left(\mu \mathrm{g} \mathrm{g}^{-1} \mathrm{~min}^{-1}\right.$ ) was assessed by the amount of NPP generated from the fresh weight of needles hydrolyzed pNPP in unit time.

Soluble protein content was determined using the Coomassie Brilliant Blue method (Zheng 2006). We took a random sample of $0.25 \mathrm{~g}$ needles, ground them in liquid nitrogen and added $4 \mathrm{ml}$ pre-cooled distilled water. Then, homogenate was transferred into centrifuge tubes and centrifuged for $15 \mathrm{~min}$ at 4,000 rpm. The supernatant ( $1 \mathrm{ml})$ was taken and $5 \mathrm{ml}$ of $\mathrm{G}-250$ Coomassie Brilliant Blue reagent was added. After shaking well and letting the mixture settle for $2 \mathrm{~min}$, the absorbance was recorded at $595 \mathrm{~nm}$, using distilled water as a blank. The fresh weight (FW) protein content ( $\mathrm{mg}$ $\mathrm{g}^{-1}$ ) of samples was determined by comparison with standard protein curves.

The total chlorophyll content was analyzed using ethanol-acetone extraction method (Zhang 1986). We took $0.05 \mathrm{~g}$ needles from each treatment and replicate, cut them into small pieces ( 2 to $3 \mathrm{~mm}$ long), placed the pieces in a tube, and added 10 $\mathrm{ml}$ of ethanol-acetone mixture $(1: 1 \mathrm{v} / \mathrm{v})$. The tubes were placed in the dark at room temperature $\left(25^{\circ} \mathrm{C}\right)$ until the materials turned completely white (shaken several times during this period). 


\section{Analysis of nutrient contents}

The cuttings in each treatment were harvested after 2 months of stress treatment by flushing the fine sand through the opening at the bottom of the pot with water. The roots in each pot patch were bundled together before pulling out the cuttings. All roots from the different patches were harvested separately, cleaned with distilled water, quickly dried with paper towels, and the fresh mass was determined. The fresh masses of stems and leaves were also determined separately. For nutrient analyses, oven-dried plant samples (leaf, stem, and root in each pot) were ground to pass through a $1 \mathrm{~mm}$ mesh, and triplicate samples were analyzed for $P$, Nitrogen $(N)$, Potassium (K), Calcium (Ca) and Magnesium (Mg). The $P$ and $K$ contents were extracted by wet ashing of $0.2 \mathrm{~g}$ plant material in an acid mixture consisting of $10 \mathrm{ml}$ $\mathrm{H}_{2} \mathrm{SO}_{4}, 3 \mathrm{ml} \mathrm{HNO}_{3}$, and $1 \mathrm{ml} \mathrm{HClO}_{4}$, following the method of Jackson (1958). Phosphorous content was determined following the molybdenum-blue method and $\mathrm{K}$ content by flame photometry. Total $\mathrm{N}$ content was determined by using the micro-Kjeldahl technique. $\mathrm{Ca}$ and $\mathrm{Mg}$ contents were measured using atomic absorption spectrophotometry.

\section{Data analysis}

The nutrient concentration of the P-poor and P-rich roots was calculated as the nutrient content of the samples divided by the dry mass of the roots. Aboveground nutrient concentration was determined as the nutrient content of needles and stems divided by their respective dry masses. A two-way ANOVA was performed to examine differences in nutrient concentration between patches and $P$ treatments for each clone. When the interaction effect was significant, a one-way ANOVA was performed for each patch and clone. In addition, physiological plasticity was determined by dividing the $\mathrm{P}$ concentration of roots (root $P$ divided by root dry mass) in the $\mathrm{P}$-rich patch by that in the P-poor patch, and a one-way ANOVA was performed to examine differences among heterogeneous $P$ treatments.

For biochemical changes in the needles of the two Chinese fir clones in response to heterogeneous $\mathrm{P}$ supply over time, a repeated measures ANOVA was performed using the following general linear model (eqn. 1):

$$
Y_{i j k}=\mu+\beta_{i}+\lambda_{j}+(\beta \lambda)_{i_{j}}+\varepsilon_{j(i)}+\varepsilon_{j(k)}
$$

where $Y_{\mathrm{ijk}}$ is the chlorophyll content, soluble protein, APase activity and MDA, $\mu$ is the overall mean, $\beta_{\mathrm{i}}$ is the effect of the between-subject factors, $i$ is the $\mathrm{P}$ treatment and clones, $\lambda_{j}$ is the effect of the withinsubject factor, $j$ is the stress period, $(\beta \lambda)_{\mathrm{ij}}$ is the interaction of the between- and withinsubject factors, $\varepsilon_{j(\mathrm{i})}$ and, $\varepsilon_{j(\mathrm{k})}$ are random errors of the between- and within-subjects factors, respectively, and $k$ is the number of replicates. Mauchly's test of sphericity was used to check the homogeneity of variance assumption; when violated, the degrees of freedom for testing the significance of the within-subject factors were adjusted using a Huynh-Feldt correction factor, which is less biased than other correction factors (Davis 2002). Means that exhibited significant differences were compared using Tukey's HSD test $(p=0.05)$. All statistical analyses were conducted using the software SPSS ${ }^{\circledast} 17$ for Windows (Release 2009 - SPSS Inc.,Chicago, USA).

\section{Results}

\section{Nutrient uptake and physiological plasticity}

For both clones, significant differences ( $\mathrm{p}$ $<0.01$ ) were detected in the concentrations of $\mathrm{P}, \mathrm{K}$, and $\mathrm{Ca}$ in the roots between $\mathrm{P}$-poor and $\mathrm{P}$-rich patches, but not significant difference were found for $\mathrm{N}$ and $\mathrm{Mg}$. Roots of both clones absorbed more P, K, and $\mathrm{Ca}$ in the P-poor than in the P-rich patch, which varied with $P$ treatments. For the low P-tolerant clone (M1), the concentrations of $\mathrm{P}$ and $\mathrm{K}$ in partly $\mathrm{P}$-starved roots (P-poor patch) were significantly higher with the insoluble $P$ supply than with the normal $\mathrm{P}$ supply, whereas the concentrations of $\mathrm{N}, \mathrm{Ca}$, and $\mathrm{Mg}$ remained unaffected by the heterogeneous $P$ supply (Tab. 1). For P-replete roots (P-rich patch), the concentrations of $K$ and $C a$ were significantly higher with insoluble $\mathrm{P}$ ( $\mathrm{P} 1$ and $\mathrm{P} 2)$

Tab. 1 - Effect of heterogeneous $\mathrm{P}$ supply on root nutrient concentration ( $\mathrm{mg} \mathrm{g}^{-1}$, Dry Mass) of low $\mathrm{P}$-tolerant Chinese fir clone $\mathrm{M} 1$ together with physiological plasticity (mean $\pm \mathrm{SE})$. (Po): No P+P; (P1): Low Fe-P + P; (P2): High Fe-P + P; (P3): Normal P + P. For each nutrient element and main effect of patches, means followed by the same letter(s) within a row are not significantly different ( $p>0.05)$.

\begin{tabular}{|c|c|c|c|c|}
\hline Nutrients & Treatments & P-poor patch & P-rich patch & Plasticity \\
\hline \multirow[t]{5}{*}{$\mathrm{P}$} & No $P+P$ & $0.66 \pm 0.02^{a}$ & $0.45 \pm 0.01^{a}$ & $0.68 \pm 0.03^{a}$ \\
\hline & Low Fe-P + P & $0.57 \pm 0.02^{b}$ & $0.46 \pm 0.02^{a}$ & $0.80 \pm 0.04^{a}$ \\
\hline & High Fe-P + P & $0.63 \pm 0.02^{a b}$ & $0.46 \pm 0.01^{a}$ & $0.72 \pm 0.04^{a}$ \\
\hline & Normal $P+P$ & $0.48 \pm 0.01^{c}$ & $0.41 \pm 0.01^{a}$ & $0.84 \pm 0.04^{a}$ \\
\hline & Mean (patch) & $0.59 \pm 0.02^{a}$ & $0.44 \pm 0.01^{b}$ & - \\
\hline \multirow[t]{5}{*}{$\mathrm{N}$} & No $P+P$ & $11.48 \pm 1.21^{a}$ & $12.03 \pm 0.43^{a}$ & $1.08 \pm 0.14^{a}$ \\
\hline & Low Fe-P + P & $13.16 \pm 1.44^{a}$ & $13.23 \pm 0.97^{a}$ & $1.01 \pm 0.05^{a}$ \\
\hline & High Fe-P + P & $10.70 \pm 0.35^{a}$ & $12.97 \pm 0.22^{a}$ & $1.22 \pm 0.06^{a}$ \\
\hline & Normal $P+P$ & $12.23 \pm 0.52^{a}$ & $12.81 \pm 0.75^{a}$ & $1.05 \pm 0.09^{a}$ \\
\hline & Mean (patch) & $11.89 \pm 0.51^{a}$ & $12.76 \pm 0.31^{a}$ & - \\
\hline \multirow[t]{5}{*}{$\mathrm{K}$} & No $P+P$ & $18.57 \pm 0.12^{b}$ & $8.73 \pm 1.00^{a}$ & $0.47 \pm 0.05^{a}$ \\
\hline & Low Fe-P + P & $17.92 \pm 0.21^{b}$ & $13.60 \pm 0.93^{b}$ & $0.76 \pm 0.05^{b}$ \\
\hline & High Fe-P + P & $18.64 \pm 0.28^{b}$ & $12.99 \pm 0.86^{b}$ & $0.70 \pm 0.04^{a b}$ \\
\hline & Normal P + P & $14.12 \pm 0.75^{a}$ & $14.85 \pm 0.40^{b}$ & $1.06 \pm 0.08^{c}$ \\
\hline & Mean (patch) & $17.31 \pm 0.59^{a}$ & $12.54 \pm 0.78^{b}$ & - \\
\hline \multirow[t]{5}{*}{$\mathrm{Ca}$} & No $P+P$ & $0.79 \pm 0.04^{a}$ & $0.49 \pm 0.03^{a}$ & $0.62 \pm 0.07^{a}$ \\
\hline & Low Fe-P + P & $0.70 \pm 0.01^{a}$ & $0.56 \pm 0.03^{a b}$ & $0.81 \pm 0.04^{\mathrm{ab}}$ \\
\hline & High Fe-P + P & $0.67 \pm 0.06^{a}$ & $0.77 \pm 0.05^{c}$ & $1.18 \pm 0.14^{b}$ \\
\hline & Normal $P+P$ & $0.71 \pm 0.01^{a}$ & $0.70 \pm 0.03^{b c}$ & $0.99 \pm 0.06^{b}$ \\
\hline & Mean (patch) & $0.72 \pm 0.02^{a}$ & $0.63 \pm 0.04^{b}$ & - \\
\hline \multirow[t]{5}{*}{$\mathrm{Mg}$} & No $P+P$ & $0.12 \pm 0.01^{a}$ & $0.11 \pm 0.01^{a}$ & $0.96 \pm 0.16^{a}$ \\
\hline & Low Fe-P + P & $0.12 \pm 0.01^{a}$ & $0.11 \pm 0.003^{a}$ & $1.02 \pm 0.15^{a}$ \\
\hline & High Fe-P + P & $0.13 \pm 0.01^{a}$ & $0.11 \pm 0.01^{a}$ & $0.83 \pm 0.07^{a}$ \\
\hline & Normal $\mathrm{P}+\mathrm{P}$ & $0.10 \pm 0.01^{a}$ & $0.11 \pm 0.003^{a}$ & $1.10 \pm 0.09^{a}$ \\
\hline & Mean (patch) & $0.12 \pm 0.01^{a}$ & $0.11 \pm 0.002^{a}$ & - \\
\hline
\end{tabular}

and normal $P\left(P_{3}\right)$ supplies than with $P$ starved roots (Po). As a whole, this clone did not show physiological plasticity for any nutrients analyzed except for $\mathrm{K}$ and $\mathrm{Ca}$, for which partial P-starvation resulted in uble $\mathrm{P}$ and normal $\mathrm{P}$ supply conditions (Tab. 1).

For the clone adapted to decouple fixed $\mathrm{P}$ (M4), the concentration of $P$ in partly $P$ starved roots was significantly higher with the high insoluble $\mathrm{P}$ supply $\left(\mathrm{P}_{2}\right)$ than the low insoluble $\mathrm{P}$ supply $(\mathrm{P} 1)$ and $\mathrm{P}$-deprived patch $(\mathrm{Po})$ but was comparable similar to the normal $\mathrm{P}$ supply ( $\mathrm{P}_{3}-$ Tab. 2). The concentration of $\mathrm{Ca}$ was 1.5 times higher with the insoluble $\mathrm{P}$ supply than in the P-deprived patch. Heterogeneous $\mathrm{P}$ supply did not affect the concentrations of $\mathrm{N}, \mathrm{K}$, and Mg (Tab. 2). For P-replete roots, the concentrations of $P$ and $C a$ were significantly higher when part of the root was grown with an insoluble $P$ supply than with a total absence of P. As a whole, roots of $\mathrm{M}_{4}$ seedlings did not show physiological plasticity, particularly in acquisition of $P$, which was spatially heterogeneous in our experiment. Nonetheless, physiological plasticity appeared to be low for $\mathrm{N}$ with the high level of insoluble $\mathrm{P}\left(\mathrm{P}_{2}\right)$ and normal $\mathrm{P}\left(\mathrm{P}_{3}\right)$ supplies, for $\mathrm{K}$ under low $\mathrm{P}$ supply $(\mathrm{P} 1)$ and for Ca with P-starvation (Po) and low level of insoluble $\mathrm{P}(\mathrm{P} 1$ ) supplies (Tab. 2).

\section{Nutrient allocation}

Nutrient accumulation in the needles and significantly lower uptake than under insol- 
Tab. 2 - Effect of heterogeneous $\mathrm{P}$ supply on root nutrient concentration ( $\mathrm{mg} \mathrm{g}^{-1}$, Dry Mass) of Chinese fir clone $\mathrm{M} 4$ adapted to decoupling fixed $\mathrm{P}$ together with physiological plasticity (mean $\pm \mathrm{SE})$. $(\mathrm{Po})$ : No P+P; $\left(\mathrm{P}_{1}\right)$ : Low Fe-P + P; $\left(\mathrm{P}_{2}\right)$ : High Fe-P $+\mathrm{P} ;\left(\mathrm{P}_{3}\right)$ : Normal $P+P$. For each nutrient element and main effect of patches, means followed by the same letter(s) within a row are not significantly different $(p>0.05)$.

\begin{tabular}{|c|c|c|c|c|}
\hline Nutrients & Treatments & P-poor patch & P-rich patch & Plasticity \\
\hline \multirow[t]{5}{*}{$P$} & No $P+P$ & $0.33 \pm 0.02^{a}$ & $0.29 \pm 0.003^{a}$ & $0.89 \pm 0.04^{a}$ \\
\hline & Low Fe-P + P & $0.39 \pm 0.02^{a b}$ & $0.39 \pm 0.02^{b}$ & $1.00 \pm 0.10^{a}$ \\
\hline & High Fe-P + P & $0.49 \pm 0.01^{c}$ & $0.37 \pm 0.003^{b}$ & $0.77 \pm 0.02^{a}$ \\
\hline & Normal $P+P$ & $0.44 \pm 0.02^{b c}$ & $0.43 \pm 0.02^{b}$ & $0.99 \pm 0.07^{a}$ \\
\hline & Mean (patch) & $0.41 \pm 0.02^{a}$ & $0.37 \pm 0.02^{b}$ & - \\
\hline \multirow[t]{5}{*}{$\mathrm{N}$} & No $P+P$ & $12.43 \pm 0.26^{a}$ & $14.00 \pm 0.02^{a}$ & $1.13 \pm 0.02^{a}$ \\
\hline & Low Fe-P + P & $12.06 \pm 0.31^{\mathrm{a}}$ & $13.35 \pm 0.17^{\mathrm{a}}$ & $1.11 \pm 0.04^{a}$ \\
\hline & High Fe-P + $P$ & $15.06 \pm 1.15^{a}$ & $13.10 \pm 0.61^{\mathrm{a}}$ & $0.88 \pm 0.04^{b}$ \\
\hline & Normal $P+P$ & $14.88 \pm 0.74^{a}$ & $12.07 \pm 1.01^{\mathrm{a}}$ & $0.81 \pm 0.05^{b}$ \\
\hline & Mean (patch) & $13.61 \pm 0.51^{a}$ & $13.13 \pm 0.33^{a}$ & - \\
\hline \multirow[t]{5}{*}{$\mathrm{K}$} & No $P+P$ & $17.18 \pm 0.47^{a}$ & $12.66 \pm 0.07^{\mathrm{a}}$ & $0.74 \pm 0.02^{a}$ \\
\hline & Low Fe-P $+P$ & $16.75 \pm 0.50^{\mathrm{a}}$ & $14.05 \pm 0.70^{a}$ & $0.84 \pm 0.02^{a}$ \\
\hline & High Fe-P $+P$ & $17.13 \pm 0.84^{a}$ & $14.09 \pm 0.11^{\mathrm{a}}$ & $0.83 \pm 0.05^{a}$ \\
\hline & Normal P + P & $14.91 \pm 1.05^{\mathrm{a}}$ & $14.49 \pm 0.72^{\mathrm{a}}$ & $0.98 \pm 0.04^{b}$ \\
\hline & Mean (patch) & $16.49 \pm 0.43^{a}$ & $13.82 \pm 0.30^{b}$ & \\
\hline \multirow[t]{5}{*}{$\mathrm{Ca}$} & No $P+P$ & $0.66 \pm 0.02^{a}$ & $0.33 \pm 0.03^{a}$ & $0.49 \pm 0.04^{\mathrm{a}}$ \\
\hline & Low Fe-P $+P$ & $0.89 \pm 0.07^{b c}$ & $0.39 \pm 0.04^{\mathrm{a}}$ & $0.44 \pm 0.08^{a}$ \\
\hline & High Fe-P + P & $1.02 \pm 0.05^{c}$ & $0.73 \pm 0.06^{\mathrm{b}}$ & $0.71 \pm 0.07^{a b}$ \\
\hline & Normal $P+P$ & $0.78 \pm 0.01$ ab & $0.71 \pm 0.06^{b}$ & $0.91 \pm 0.09^{b}$ \\
\hline & Mean (patch) & $0.84 \pm 0.04^{a}$ & $0.54 \pm 0.06^{b}$ & \\
\hline \multirow[t]{5}{*}{$\mathrm{Mg}$} & No $P+P$ & $0.10 \pm 0.00^{a}$ & $0.09 \pm 0.00^{\mathrm{a}}$ & $0.88 \pm 0.03^{a}$ \\
\hline & Low Fe-P + P & $0.10 \pm 0.01^{\mathrm{a}}$ & $0.10 \pm 0.003^{a}$ & $0.97 \pm 0.10^{a}$ \\
\hline & High Fe-P $+P$ & $0.11 \pm 0.01^{a}$ & $0.10 \pm 0.01^{\mathrm{a}}$ & $0.92 \pm 0.11^{a}$ \\
\hline & Normal P + P & $0.10 \pm 0.01^{\mathrm{a}}$ & $0.09 \pm 0.00^{\mathrm{a}}$ & $0.91 \pm 0.11^{\mathrm{a}}$ \\
\hline & Mean (patch) & $0.10 \pm 0.003^{a}$ & $0.09 \pm 0.003^{a}$ & - \\
\hline
\end{tabular}

Fig. 2 - Nutrient accumulation (mg g-1. per plant, Dry Mass) in needles and stems of low P-tolerant Chinese fir genotypes, M1 and $\mathrm{M} 4$, in response to heterogeneous P supply (mean $\pm \mathrm{SE})$.
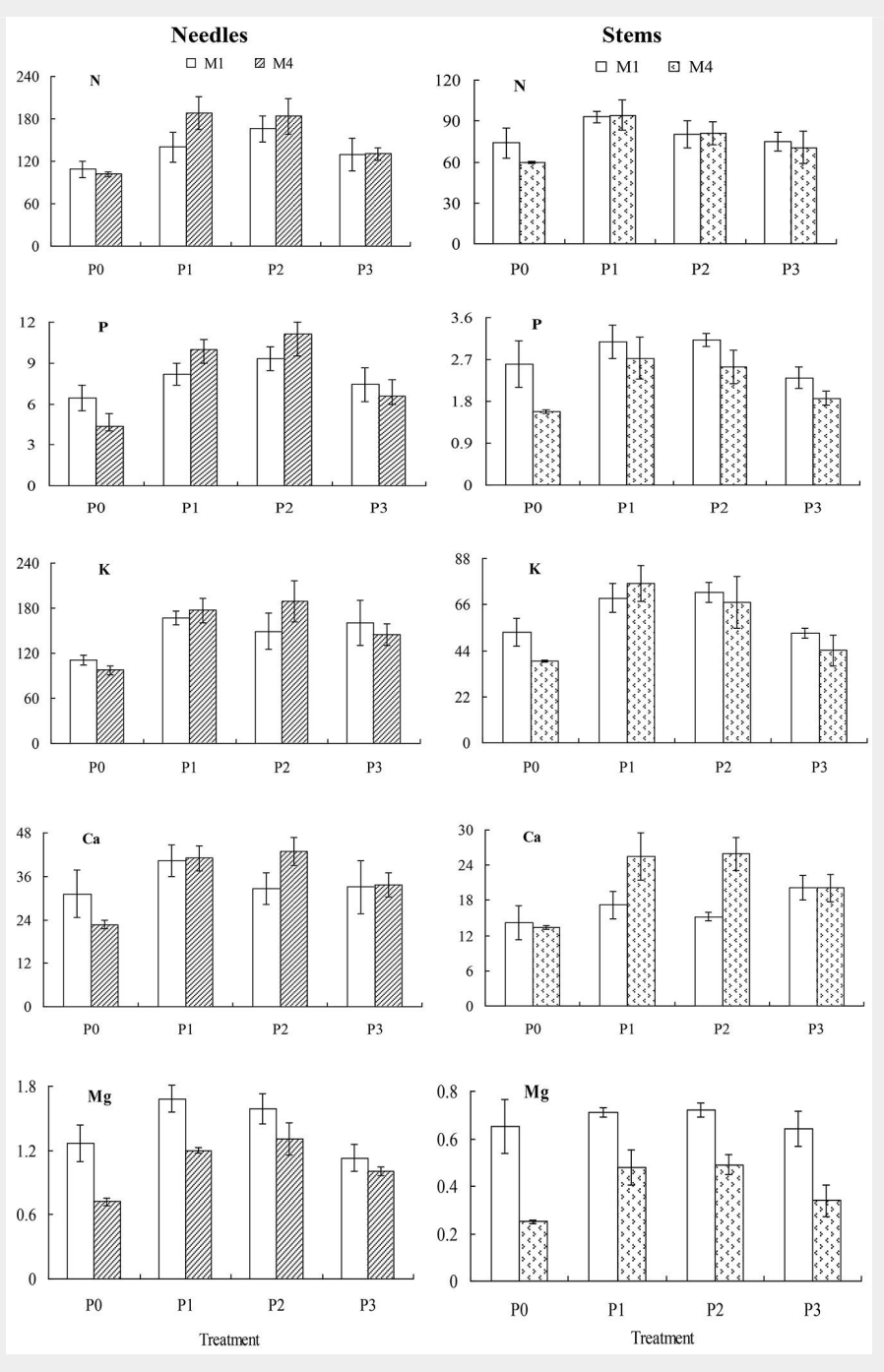

stem showed differential responses to heterogeneous $\mathrm{P}$ supply (Fig. 2). For needles, there was no significant difference in nutrient accumulation between clones, but the effect of $P$ supply was significant for all nutrients analyzed, particularly for the clone M4. For this clone, the accumulation of $\mathrm{P}$ in the needles was 1.7 and 2.5 times higher in the patch with a high level of insoluble $P$ than the in partially P-deprived and P-replete patches, respectively. The accumulations of $\mathrm{N}, \mathrm{K}, \mathrm{Ca}$ and $\mathrm{Mg}$ were still higher in the patch with insoluble $\mathrm{P}$ than in the partially P-deprived patch but were comparable to those in the P-replete patch.

Nutrient accumulation in the stems varied significantly between clones and $\mathrm{P}$ treatments for $\mathrm{P}, \mathrm{Ca}$, and $\mathrm{Mg}$, but accumulation of $K$ in the stems varied significantly with respect to heterogeneous $\mathrm{P}$ supply, while $\mathrm{N}$ accumulation in stems remained unaffected by $\mathrm{P}$ treatment. The clone $\mathrm{M} 1 \mathrm{accu}-$ mulated more $\mathrm{P}$ in the stem than the $\mathrm{M}_{4}$ clone, while the reverse was found for $\mathrm{Ca}$ accumulation in stems particularly with an insoluble P supply (Fig. 2). Similarly, the M1 clone accumulated more $\mathrm{Mg}$ in stems than the M4 clone across all levels of the heterogeneous P supply (Fig. 2).

\section{Biochemical changes in needles}

The biochemical content of needles exhibited marked temporal variation in response to heterogeneous $P$ supply. The APase activity in needles varied significantly with respect to within-subject factors (stress period and its first and second order interactions with $\mathrm{P}$ treatment and clone $-p<0.0001$ ), as well as for betweensubject factors (clone $-p<0.0001$ ), but not $P$ treatments $(p=0.58)$. During the first 20 days of stress, the mean APase activity did not change much for any of the $P$ treatments for either clones, but the activity sharply increased in the heterogeneous $P$ supply treatment with insoluble $P$ after 40 days, and the increase was markedly higher for the M4 clone than the M1; activity sharply declined thereafter in all $P$ treatments (Fig. 3).

The MDA content also varied significantly with respect to within-subject factors (stress period and its first and second order interactions with $P$ treatment and clones, $\mathrm{p}<0.0001$ ), as well as with between-subject factors (clone and $P$ treatment, $p<0.0001$ for both). The mean MDA content sharply increased during the first 20 days of the treatments arranged with no $\mathrm{P}$ and normal $\mathrm{P}$ supply in each patch, thereafter the content declined sharply for the M1 clone (Fig. 3). The change in MDA content was slow for the treatments arranged with a high level of insoluble $P$ and normal $\mathrm{P}$ supply in each patch for the $\mathrm{M}_{1}$ clone. For the $\mathrm{M}_{4}$ clone, the initial increase in MDA content was relatively gradual but the subsequent decline was sharp for nearly all $P$ treatments.

The content of soluble protein also varied significantly with respect to within-subject 
factors (stress period and its first and second order interactions with $\mathrm{P}$ treatment and clone $-p<0.05$ ), as well as with between-subject factors (clone $-p<0.0001$ ), but not for $P$ treatments $(p=0.375)$. The mean soluble protein content sharply increased during the first 20 days of the experiment in all $P$ treatments, and the increase was markedly higher for the $\mathrm{M}_{4}$ than the M1 clone (Fig. 3). Thereafter the content declined sharply, particularly during the second 20 days. The total chlorophyll content varied significantly with respect to within-subject factors (stress period and its first and second order interactions with $\mathrm{P}$ treatment and clone $-\mathrm{p}<$ 0.05 ) but not among between-subject factors (clone $-p=0.066$ ) and for $P$ treatments $(p=0.627)$. The mean chlorophyll content increased gradually over time for the treatments with no $\mathrm{P}$ and normal $\mathrm{P}$ supply in each patch but slowly declined after 40 days for all $P$ treatments with insoluble $\mathrm{P}$ and normal $\mathrm{P}$ supply in each patch for the $\mathrm{M}_{1}$ clone (Fig. 3). For the $\mathrm{M}_{4}$ clone, the mean chlorophyll content increased rapidly during the first 20 days and then remained nearly stable for all $P$ treatments.

\section{Discussion}

Heterogeneous $\mathrm{P}$ supply had no marked influence on the rate of nutrient uptake by P-efficient Chinese fir clones, thus root physiological plasticity plays no adaptive role in $\mathrm{P}$ acquisition from localized P-replete zones. Phosphorous acquisition was more significant in terms of growth benefits than $P$ utilization, under low $P$ conditions (Hu et al. 2016). Physiological plasticity is likely more important in enhancing capture of mobile ions (nitrate) than of immobile ions (phosphate), the latter being limited more by diffusion to the root surface (Hodge 2004). Mobility of $P$ in the soil is very poor with a diffusion distance of only 1 to $2 \mathrm{~mm}$, and a diffusion coefficient in soil of about $3 \times 10^{14} \mathrm{~mol}(\mathrm{~cm} \mathrm{~s})^{-1}$ (Guo et al. 2005). Thus, enhancing ion uptake at the root surface will not necessarily result in enhanced phosphate $(\mathrm{Pi})$ capture. The plant may respond rapidly to increase capture of mobile ions before they diffuse to other roots, while a similar response is less decisive for immobile ions, thus allowing time for new root construction. This was evidenced in our study where the uptake of $\mathrm{N}$ was equally high in both heterogeneous and homogeneous $P$ supplies in each patch. Our study showed higher uptake of $\mathrm{P}$ in patches supplied with insoluble $P$ than in normal $P$ supply patches. This could be attributed to increased deployment of roots with larger surface area and volume in P-deficient patches than P-replete patches by both clones (Wu et al. 2011b). Heterogeneous $P$ supply appeared to have no impact on the uptake of most other nutrients, except $\mathrm{K}$ and $\mathrm{Ca}$. The role of these nutrients under low $P$ stress is under further investigation.

There is strong evidence in this study that
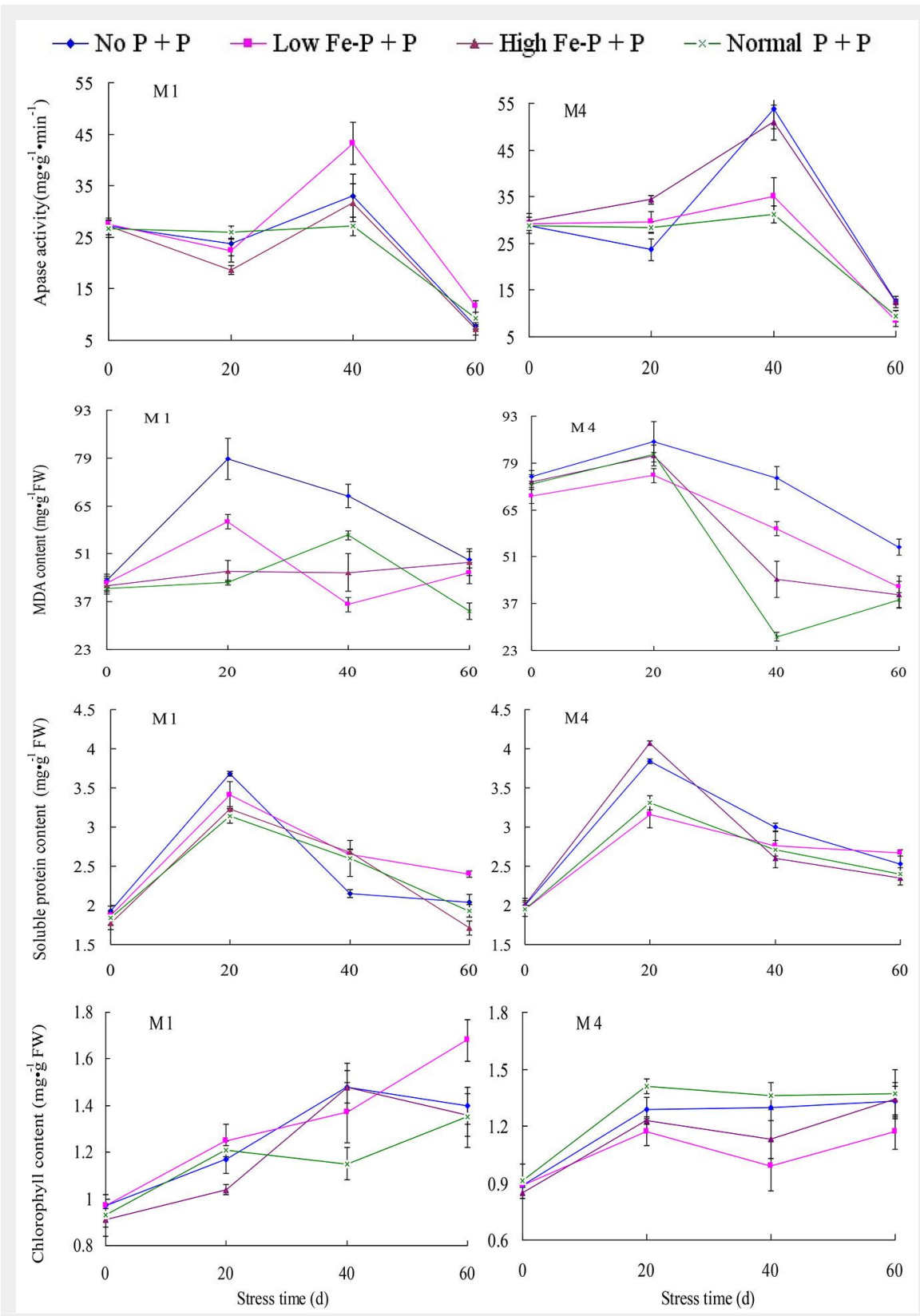

Fig. 3 - Temporal variation in APase, MDA content, soluble protein and total chlorophyll content of low P-tolerant Chinese fir clone, $M_{1}$ and $M 4$, in response to heterogeneous $\mathrm{P}$ supply over time (mean $\pm \mathrm{SE})$.

rhizospheric low $\mathrm{P}$ stress induces a number of biochemical changes in the needles of Chinese fir clones with high phosphorus efficiency. APase activity sharply increased after 40 days in the heterogeneous $P$ supply involving insoluble $\mathrm{P}$ for both $\mathrm{M} 1$ and $\mathrm{M} 4$, the increase being markedly high for the latter. APase participates in various metabolic processes in plants, particularly in hydrolyzing orthophosphate monoesters into more mobile orthophosphate anions, Pi (Vincent et al. 1992, Ye et al. 2015), and thereby remobilizing Pi from metabolically less active sites, such as old leaves and vacuoles, to young tissues. The massive use of Pi-containing fertilizers in agriculture demonstrates how the soluble $\mathrm{Pi}$ level of many soils is sub-optimal for crop growth (Plaxton \& Tran 2011). APase activ- ity in leaf tissues is, thus, believed to be related to P-use efficiency under P-limiting conditions (Wang et al. 2009). This is evidenced in this study, which found that $P$ concentrations in needles and stems were similar across all $P$ treatments as a result of remobilization. The sharp decline in APase activity with increasing duration of stress could be attributed to internal $P$ homeostasis, which in turn may reflect a conservative, long-term growth and metabolic strategy of P-efficient Chinese fir clones. For the two clones studied, we observed insignificant variation in shoot and root biomass production between P-starved and nonstarved seedlings (Wu et al. 2011b).

Our study also showed that membrane lipid oxidation, as measured by increased MDA content, occurred shortly after the 
stress was induced (20 days), but declined rapidly thereafter. Environmental stresses are often followed by increased production of reactive oxygen species that are known to damage membrane integrity. However, plants adapted to such stresses produce a suite of antioxidants to scavenge the elicited Reactive Oxygen Species (He et al. 2013). The sharp decline in MDA content with increasing stress period, particularly for the $\mathrm{M} 4$ clone might be attributed to the increased synthesis of antioxidants. It could also be associated with time to construct large root surface area and volume, which in turn enabled these clones, especially the $\mathrm{M}_{4}$ clone, to decouple fixed $\mathrm{P}$, thereby tolerating the low $\mathrm{P}$ stress, as we observed previously (Wu et al. 2011b).

There is no evidence in the present study that rhizospheric insoluble $P$ affects the synthesis of soluble protein. This can be related to effective translocation of absorbed $\mathrm{P}$ to the needles and efficient utilization of $P$, as can be seen from similar concentrations of $P$ in the needles in both the heterogeneous supply with high fixed $P$ and homogeneous supply of normal level of $\mathrm{P}$ treatments. It should be noted that these two clones produced similar quantities of shoot and root biomass in P-starved and non-starved seedlings suggesting high P-utilization efficiency (Wu et al. 2011b). Rhizospheric insoluble $\mathrm{P}$ also had no impact on chlorophyll content, but the reduction in chlorophyll content with plant age, regardless of $\mathrm{P}$ supply, might be due to mutual shading and increased ratio of older to younger leaves, as well as increased rates of dark respiration and translocation of assimilates. Our results are consistent with a previous study that showed a decline in chlorophyll content under low $\mathrm{P}$ stress $(\mathrm{He}$ et al. 2013).

\section{Conclusions}

The results of the present study did not show an increased rate of nutrient uptake in P-replete patches; thus, we conclude that root physiological plasticity does not play a role in adaptation to a heterogeneous $\mathrm{P}$ supply by enhancing $\mathrm{P}$-acquisition efficiency in P-efficient Chinese fir clones. In addition, a heterogeneous $P$ supply had no negative impact on the uptake and translocation of other nutrients to the shoots. The most interesting part of this study is the variation in nutrient uptake within the same root system depending on $P$ availability. The part of the root system that was deprived of available $P$ had $a$ higher concentration of nutrients $(P, K$, and $\mathrm{Ca}$ ) than the part of the root system supplied with normal $P$ levels. This suggests that determinate root development can occur even within the same root system in response to spatial variation in the availability of $P$ around the root system. The changes in APase activity and MDA content in needles suggest functional metabolic processes involved in enhancing $P$ efficiency in these clones. Since the two
Chinese fir clones appeared to be adapted to low P stress, mainly via root morphological plasticity as we reported earlier, they can be promoted as regeneration materials for future plantations in southern China, where the soil is deficient in $\mathrm{P}$.

\section{Acknowledgments}

This research was financially supported by the National Natural Science Foundation of China (U1405211 and 31370531) and by the Science and Technology Plan Project of Fuzhou City, China (2017-N-35).

\section{References}

Alexova R, Millar AH (2013). Proteomics of phosphate use and deprivation in plants. Proteomics 13 (3-4): 609-623. - doi: 10.1002/pmic.20 1200266

Ao JJ, Kang ZL, Yu Y (2007). Plant physiology experimental techniques. Chemical Industry Press, Beijing, China, pp. 133-134. [in Chinese]

Chen $\mathrm{H}$ (2003). Phosphatase activity and $\mathrm{P}$ fractions in soils of an 18-year-old Chinese fir (Cunninghamia lanceolata) plantation. Forest Ecology and Management 178 (3): 301-310. - doi: 10.1016/S0378-1127(02)00478-4

Davis CS (2002). Statistical methods for the analysis of repeated measurements. Springer-Verlag, New York, USA, pp. 203-298.

Guo S, Yan X, Bai B, Yu S (2005). Responses of larch seedling's photosynthetic characteristics to nitrogen and phosphorus deficiency. Chinese Journal of Applied Ecology 16 (4): 589594. [online] URL: http://europepmc.org/abstr act/med/16011149

He YL, Liu A, Tigabu M, Wu P, Ma X, Wang C, Oden PC (2013). Physiological responses of needles of Pinus massoniana elite families to phosphorus stress in acid soil. Journal of forestry research 24 (2): 325-332. - doi: 10.1007/s11676-01 30356-7

Hodge A (2004). The plastic plant: root responses to heterogeneous supplies of nutrients. New Phytologist 162 (1): 9-24. - doi: 10.1111/ j.1469-8137.2004.01015.x

Hu Z, He Z, Huang Z, Fan S, Yu Z, Wang M, Zhou $X$, Fang C (2014). Effects of harvest residue management on soil carbon and nitrogen process in Chinese fir plantation. Forest Ecology and Management 326: 163-1670. - doi: 10.1016/j.foreco.2014.04.023

Hu C, Zhao L, Zhou Z, Dong G, Zhang Y (2016). Genetic variations and correlation analysis of $\mathrm{N}$ and $\mathrm{P}$ traits in Pinus massoniana. Trees 30 (4): 1341-1350. - doi: 10.1007/s00468-016-1370-0

Jackson ML (1958). Soil chemical analysis. Prentice-Hall Inc., Englewood Cliffs, USA, pp. 460498.

McLachlan KD (1980). Acid phosphatase activity of intact roots and phosphorus nutrition in plants. (I): Assay conditions and phosphatase activity. Australian Journal of Agricultural Research 31 (3): 429-440. - doi: 10.1071/AR9800429 Miguel MA, Postma JA, Lynch JP (2015). Phene synergism between root hair length and basal root growth angle for phosphorus acquisition. Plant Physiology 167 (4): 1430-1439. - doi: 10.110 4/pp.15.00145

Plaxton WC, Tran HT (2011). Metabolic adaptations of phosphate-starved plants. Plant Physi- ology 156 (3): 1006-1015. - doi: 10.1104/pp.111.17 5281

Shenoy VV, Kalagudi GM (2005). Enhancing plant phosphorus use efficiency for sustainable cropping. Biotechnology Advances 23 (7): 501-513. doi: 10.1016/j.biotechadv.2005.01.004

Tian D, Xiang W, Chen X, Yan W, Fang X, Kang W, Dan $X$, Peng C, Peng $Y$ (2011). A long-term evaluation of biomass production in first and second rotations of Chinese fir plantations at the same site. Forestry 84 (4): 411-418. - doi: 10.109 3/forestry/cpro29

Tripathi DK, Singh VP, Prasad SM, Dubey NK, Chauhan DK, Rai AK (2016). LIB spectroscopic and biochemical analysis to characterize lead toxicity alleviative nature of silicon in wheat (Triticum aestivum L.) seedlings. Journal of Photochemistry and Photobiology B: Biology 154 (1): 89-98. - doi: 10.1016/j.jphotobiol.2015.11.008 Vincent JB, Crowder MW, Averill BA (1992). Hydrolysis of phosphate monoesters: a biological problem with multiple chemical solutions. Trends in Biochemical Sciences 17 (3): 105-110. doi: 10.1016/0968-0004(92)90246-6

Wang X, Wang Y, Tian J, Lim BL, Yan X, Liao H (2009). Overexpressing AtPAP15 enhances phosphorus efficiency in soybean. Plant Physiology 151 (1): 233-240. - doi: 10.1104/pp.109.13 8891

Wu P, Tigabu M, Ma X, Oden PC, He Y, Yu X, He Z (2011a). Variations in biomass, nutrient contents and nutrient use efficiency among Chinese fir provenances. Silvae Genetica 60 (3-4): 95-105. - doi: 10.1515/sg-2011-0014

Wu P, Ma X, Tigabu M, Wang C, Liu A, Oden PC (2011b). Root morphological plasticity and biomass production of two Chinese fir clones with high phosphorus efficiency under low phosphorus stress. Canadian Journal of Forest Research 41 (2): 228-234. - doi: 10.1139/X10-198 Wu P, Ma X, Chen Y, Lin W, Huang S, Liu L (2012). Comparison of phosphorus use efficiency among clonal test plantations of Chinese fir. Journal of Fujian Agriculture and Forestry University (Natural Science Edition) 41: 40-45. [in Chinese]

Wu P, Wang G, Farooq TH, Li Q, Zou X, Ma X (2017). Low phosphorus and competition affect Chinese fir cutting growth and root organic acid content: does neighboring root activity aggravate $\mathrm{P}$ nutrient deficiency? Journal of Soils and Sediments 17 (12): 2775-2785. - doi: 10.1007/ S11368-017-1852-8

Xie Y, Zhou Z (2002). Research advance on adaptation mechanism of forest tree to low-phosphorus stress and genetics of phosphorus efficiency. Forest Research 15 (6): 734-740. - cba: 379191.

Ye D, Li T, Liu D, Zhang X, Zheng Z (2015). P accumulation and physiological responses to different high $\mathrm{P}$ regimes in Polygonum hydropiper for understanding a P-phytoremediation strategy. Scientific Reports. 5: 17835. - doi: 10.1038/srep 17835

Zhang XZ (1986). Determination of chlorophyll content in plant tissue. Liaoning Agricultural Science and Technology 3: 26-28. [in Chinese]

Zheng BS (2006). Plant physiology and biochemistry of modern research techniques. China Meteorological Press, Beijing, China, pp. 107-109. [in Chinese] 
Zhou L, Shalom AD, Wu P, Li S, Jia Y, Ma X (2015). Litterfall production and nutrient return in different-aged Chinese fir (Cunninghamia lanceolata) plantations in South China. Journal of Forestry Research 26 (1): 79-89. - doi: 10.1007/s11 676-014-0011-y
Zhou L, Shalom AD, Wu P, He Z, Liu C, Ma X (2016). Biomass production, nutrient cycling and distribution in age-sequence Chinese fir (Cunninghamia lanceolata) plantations in subtropical China. Journal of Forestry Research 27 (2): 357-368. - doi: 10.1007/s11676-015-0167-0
Zou X, Wu P, Chen N, Wang P, Ma X (2014). Chinese fir root response to spatial and temporal heterogeneity of phosphorus availability in the soil. Canadian Journal of Forest Research 45 (4): 402-410. - doi: 10.1139/cjfr-2014-0384 